\title{
Central compaction in the process of lens growth as indicated by lamellar cataract
}

\author{
NICHOLAS A P BROWN, JOHN M SPARROW, AND ANTHONY J BRON \\ From the Nuffield Laboratory of Ophthalmology, Walton Street, Oxford OX2 6AW
}

summary The lens growth through life is the net result of surface accretion partially offset by $\overrightarrow{0}$ central compaction. Compaction has previously been shown to affect the cortex. The present study $\overrightarrow{\vec{\overrightarrow{ }}}$ examines compaction in the nucleus by measuring the change in dimensions of congenital lamellar $\omega_{\mathscr{\rho}}$ cataract with time and by comparing the different dimensions of dominantly inherited lamellar $\frac{0}{0}$. cataract in individuals of different ages in the same family. It is now shown that compaction affects the nucleus at a decreasing rate with increasing age and that the rate of compaction of lamellar $N$ cataracts is faster the greater diameter of the affected lamella. It is concluded that compaction of on lens fibres towards the centre of the lens affects all regions of the cortex and nucleus in youth and $\infty$ that the compaction becomes largely or completely confined to the cortex in middle age and $\bigcirc$ beyond. The shape of the lamellar cataract changes from a lenticular shape in youth to a rounded $\vec{c}$ shape with increasing age. This accounts for the development of the peripheral divergence of the $\stackrel{\Sigma}{<}$ zones of discontinuity of the cortex, which allows the lens to remain emmetropic with increasing age in spite of changes in surface curvature.

The lens grows at a steady rate through life ${ }^{1-6}$ by the process of surface accretion of new lens fibres offset by a central compaction of fibres towards the nucleus. An estimate of the compacting behaviour of the fibres in the cortex has previously been obtained by observing traumatic cataracts and glaucoma flecks. ? These opacities occur initially in the immediately subcapsular region and sink into the lens with time. The study showed that the opacities sink in at approximately twice the rate at which the lens is growing, which implies that compaction is occurring at half the rate of the surface accretion. The study did not show to what depth in the lens the compaction proceeds. Is it a phenomenon limited to the cortex, or does compaction proceed all the way to the centre of the lens, or to some point in between? Does age affect this process, with compaction going all the way to the lens centre in youth and perhaps ceasing at a more superficial level in old age?

The present study examines congenital lamellar

Correspondence to Mr N A P Brown, FRCS.

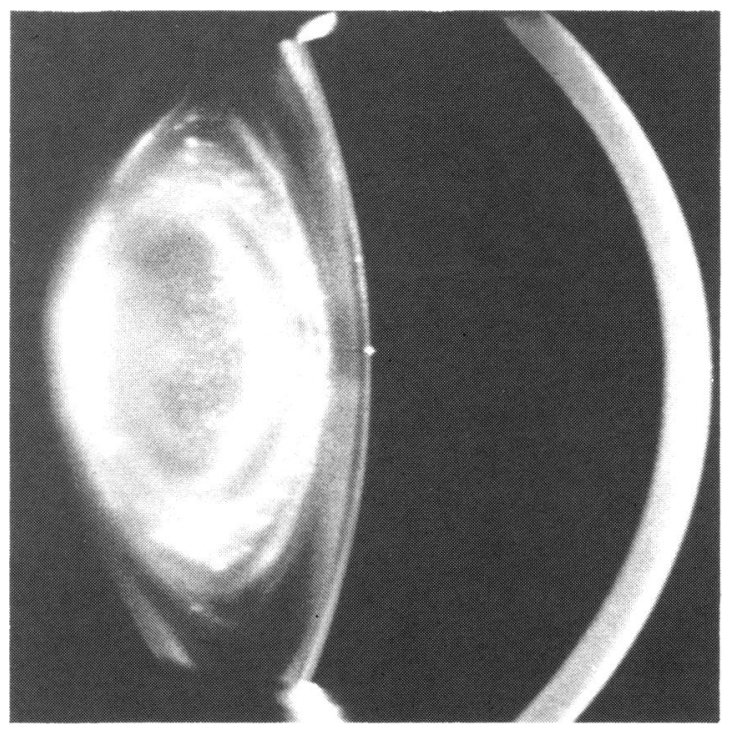

Fig. 1 Subject aged 9 at first examination. 


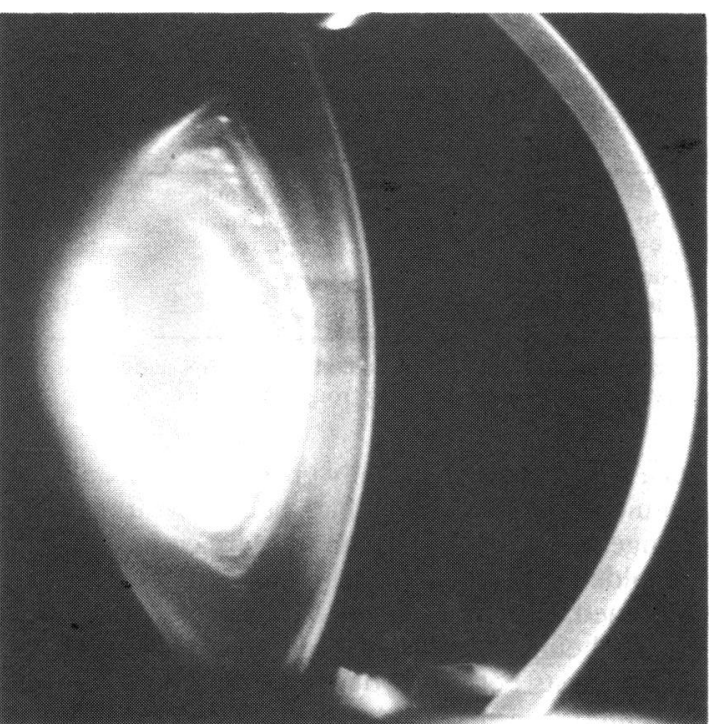

Fig. 2 The same subject as in Fig. 1 at the age of 14.

nuclear cataracts and their change with time in order to define how compaction affects the nucleus and to attempt to answer these questions.

\section{Materials and methods}

Subjects with congenital lamellar cataract (Figs. 1 and 2) were included when they had at least two slitimage photographic examinations at an interval of five or more years. A second group of subjects (Figs.

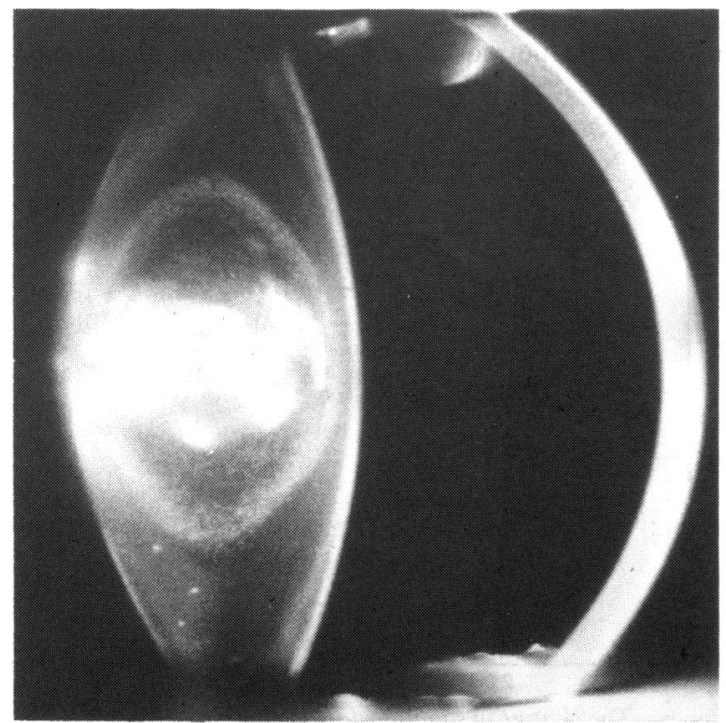

Fig. 3 Familial congenital cataract in a subject aged 10.

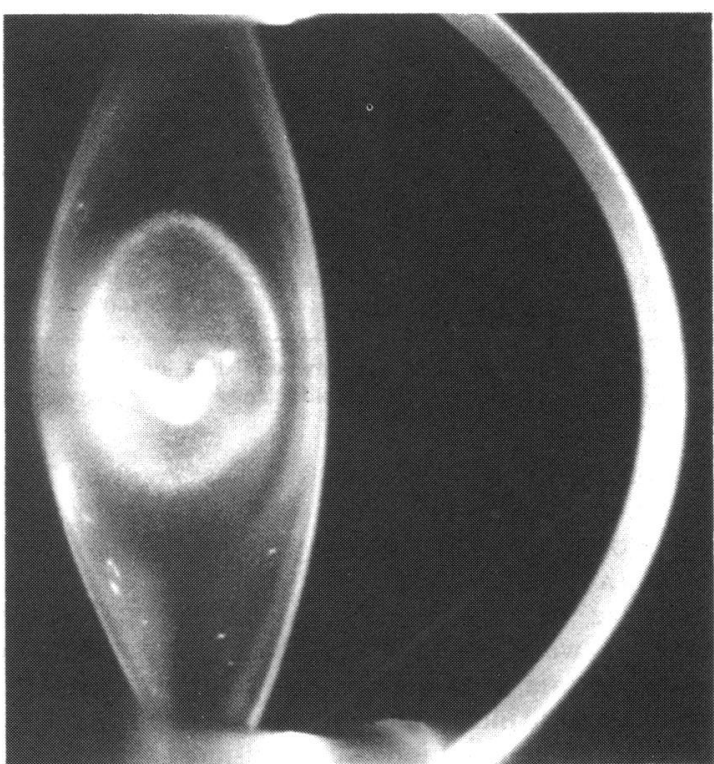

Fig. 4 A subject in the same family as Fig. 3 aged 19.

3 and 4) were included in which only single observations had been made in subjects who were members of a family with dominant congenital cataract. The inclusion of the familial group is justifiable if it can be presumed that the expression of the cataract was identical at birth in the separate individuals within each family. Some of the cataracts examined affected the complete nucleus and others only part of the central region of the nucleus. The extent of the nucleus affected in the familial group was the same in each individual in a particular family.

The subjects were examined by slit-image photography and then measurements made from negatives by a previously described technique ${ }^{8}$ The equatorial diameter and the sagittal width of the outermost affected lamella were measured. The measurements were corrected for camera magnifications but not for the magnification of the cornea or of the lens cortex. Two negatives were available for each eye in most cases, and the mean of the two measurements was taken. Left and right eyes of the same individual were found to behave in a very similar fashion and so the means of the left and right results were taken to illustrate the behaviour of the cataract in that individual (Figs. 5 and 6). (The averages were not used in the statistical analysis.)

Satisfactory negatives for measurement were obtained of five individuals on separate occasions and of one individual with a third examination. Four families with individuals of different ages were measured. 
Table 1 Youngerlenses versus older lenses, paired $\mathrm{t}$ tests

\begin{tabular}{|c|c|c|c|c|c|c|}
\hline & \multicolumn{3}{|c|}{ Sagittal width } & \multicolumn{3}{|c|}{ Equatorial diameter } \\
\hline . & Indiv & Fam & Both & Indiv & Fam & Both \\
\hline Mean younger & $2 \cdot 81 \mathrm{~mm}$ & $2.60 \mathrm{~mm}$ & $2.70 \mathrm{~mm}$ & $6.60 \mathrm{~mm}$ & $5.04 \mathrm{~mm}$ & $5.74 \mathrm{~mm}$ \\
\hline Mean older & $2.66 \mathrm{~mm}$ & $1.98 \mathrm{~mm}$ & $2 \cdot 30 \mathrm{~mm}$ & $6 \cdot 18 \mathrm{~mm}$ & $3.66 \mathrm{~mm}$ & $4 \cdot 80 \mathrm{~mm}$ \\
\hline Mean age diff & $8 \cdot 6 \mathrm{yr}$ & $14 \cdot 8 \mathrm{yr}$ & $11.9 \mathrm{yr}$ & $9 \cdot 0 \mathrm{yr}$ & $19 \cdot 0 \mathrm{yr}$ & $14 \cdot 7 \mathrm{yr}$ \\
\hline Mean compaction per year & $17 \mu \mathrm{m}$ & $42 \mu \mathrm{m}$ & $34 \mu \mathrm{m}$ & $47 \mu \mathrm{m}$ & $73 \mu \mathrm{m}$ & $64 \mu \mathrm{m}$ \\
\hline p Value & 0.09 & $0 \cdot 003$ & $0 \cdot 001$ & $0 \cdot 0005$ & $0 \cdot 001$ & $0 \cdot 001$ \\
\hline
\end{tabular}

Key to table: Indiv=individual patients, serial data, lens size when younger versus lens size when older. Fam =family groups, lens size of younger members versus lens size of older members. $\mathrm{p}$ Value $=$ significance level of paired $t$ test comparing groups.

\section{Results}

CHANGES IN THE DIMENSIONS OF LAMELLAR CATARACTS WITH AGE

The size differences between younger and older cataracts were examined statistically. Sagittal width and equatorial diameter were considered separately. The data from individual patients who had had two or more serial examinations were considered separately from those patients who were members of a family group. For serial examinations the initial cataract size was compared with subsequent cataract size in the

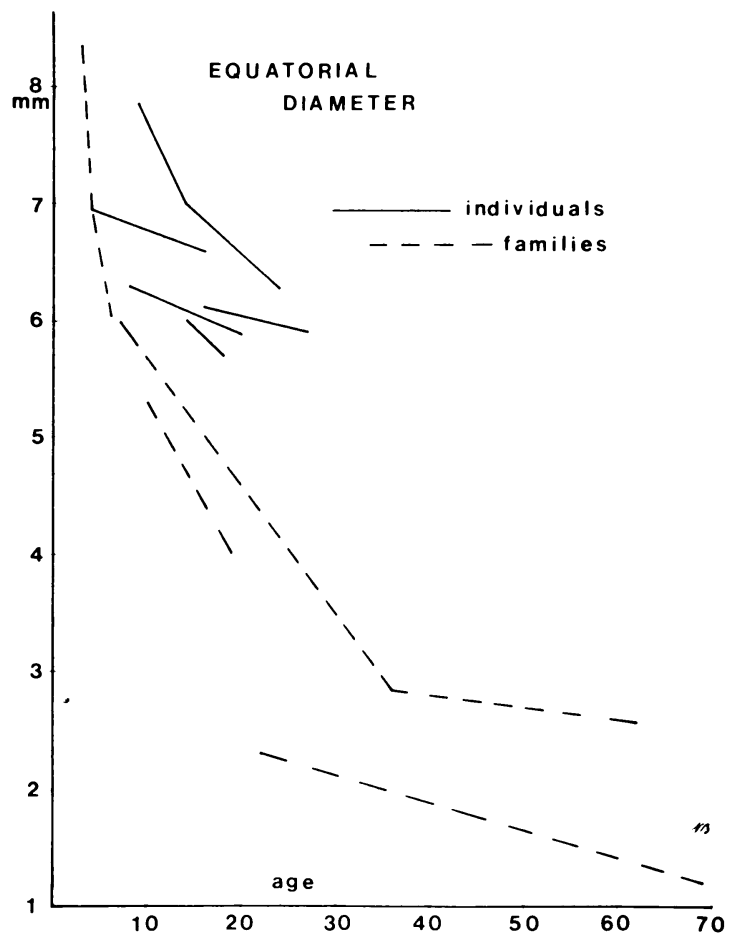

Fig. 5 The change in equatorial diameter of lamellar cataracts with age. same eye. Within the family groups, where only one examination per patient had been performed, the younger members of the family were compared with the older members. Finally the two groups were combined, with the individual patients and the family groups being considered together. The results of paired $t$ tests between younger and older lenses are presented in Table 1. Apart from one group these results all showed a statistically significant reduction in cataract size at the $1 \%$ level. The exception was the group for serial measurement of the sagittal width of individual lenses over time. Although there was a trend towards a reduction in cataract size, this trend did not reach the $5 \%$ significance level. (This was the smallest group, and this fact may account for the statistically non-significant result.) These results confirm the impression that lamellar cataracts decrease in size over time.

RELATIONSHIP BETWEEN SAGITTAL WIDTH AND EQUATORIAL DIAMETER

A strong correlation existed between the sagittal width and the equatorial diameter of individual

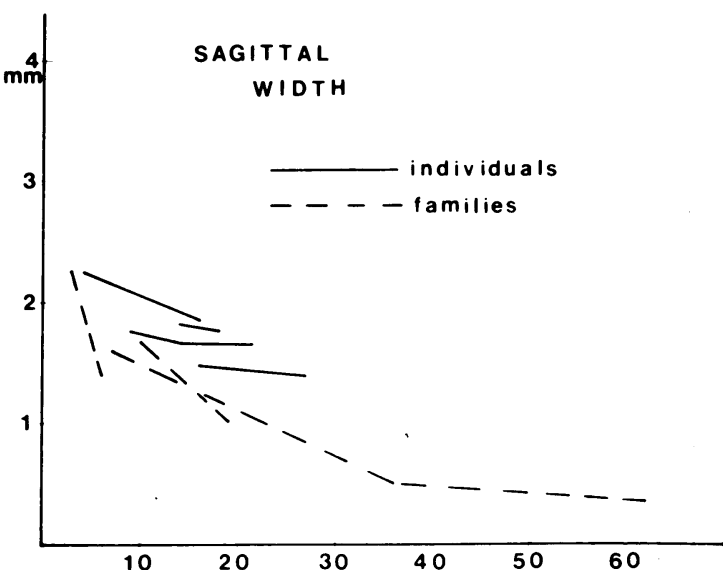

Fig. 6 The change in sagittal width of lamellar cataracts with age. 


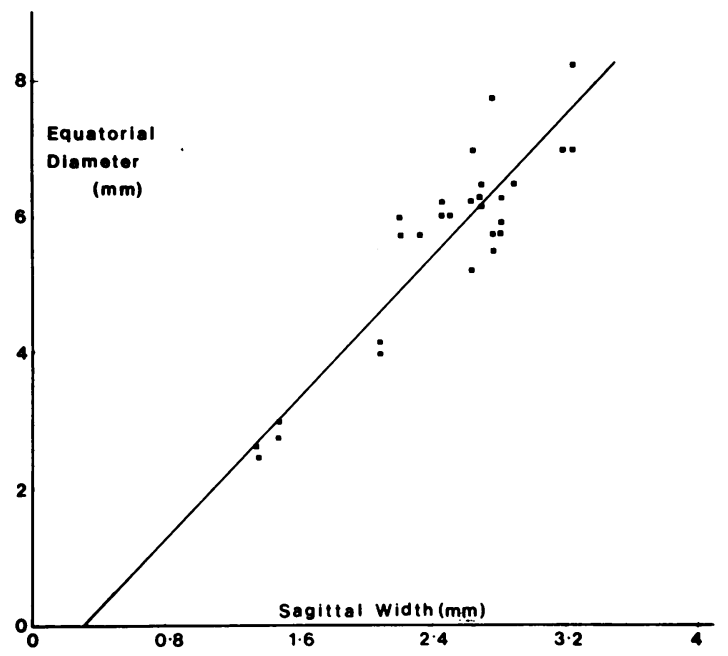

Fig. 7 Correlation between sagittal widths and equatorial diameter of lamellar cataracts.

lamellar cataracts. The linear correlation coefficient between these variables was $0 \cdot 90, \mathrm{p}<0 \cdot 0001$ ). The linear regression line for the data was described by the function $\mathrm{Y}=2.56 \times-0.75$ ( $\mathrm{SD}$ for slope and $\mathrm{Y}$ intercept are 0.24 and 0.13 respectively. This regression line (Fig. 7) did not pass through the origin, and this relationship indicates that, the smaller the cataract is, the less oval and more round is its shape on sagittal section. This fact has important consequences for the refractive power of the growing lens as a whole, as discussed below.

\section{RELATIONSHIP BETWEEN AGE OF PATIENT AND} RATE OF CATARACT SHRINKAGE

Polynomial regression analysis of mean age against the rate of compaction of cataracts revealed a trend of decreasing rate of compaction of cataract with increasing age. A summary of the regression analysis for first order (linear) and second order (quadratic) polynomials is presented in Table 2 . The linear

Table 2 Polynominal regression analysis of age versus rate of cataract shrinkage

\begin{tabular}{|c|c|c|c|c|c|c|}
\hline & \multicolumn{3}{|c|}{ Sagittal width } & \multicolumn{3}{|c|}{ Equatorial diameter } \\
\hline & Indiv & Fam & Both & Indiv & Fam & Both \\
\hline $\begin{array}{l}\text { Linear corr } \\
\text { Quad corr }\end{array}$ & $\begin{array}{l}0.73 \\
0.80\end{array}$ & $\begin{array}{l}0.61 \\
0.74\end{array}$ & $\begin{array}{l}0.46 \\
0.69\end{array}$ & $\begin{array}{l}0.25 \\
0.50\end{array}$ & $\begin{array}{l}0.65 \\
0.82\end{array}$ & $\begin{array}{l}0.47 \\
0.71\end{array}$ \\
\hline
\end{tabular}

Key to table: Indiv=individual patients, serial data. $\mathrm{Fam}=$ family groups. Linear corr $=$ linear correlation coefficient. Quad corr $=$ quadratic correlation coefficient.
Table 3 Polynominal regression analysis of initial cataract size versus rate of cataract shrinkage

\begin{tabular}{lllllllll}
\hline & \multicolumn{3}{l}{ Sagittal width } & & \multicolumn{3}{c}{ Equatorial diameter } \\
\cline { 2 - 3 } & Indiv & Fam & Both & & Indiv & Fam & Both \\
\hline Linear corr & $\mathbf{0 . 8 8}$ & $\mathbf{0 . 6 3}$ & 0.46 & & 0.58 & 0.75 & 0.48 \\
Quad corr & 0.89 & 0.79 & 0.61 & & 0.78 & 0.97 & 0.72
\end{tabular}

Key to table: Indiv=individual patients, serial data. $\mathrm{Fam}=$ family groups. Linear corr $=$ linear correlation coefficient. Quad corr= quadratic correlation coefficient.

regression lines all showed a typical trend of decreasing rate of cataract compaction with age. Examination of the relevant sections of the quadratic regression functions revealed a trend of rapid compaction in youth, which decreased with increasing age, and then settled down to a constant rate of compaction in about the third decade of life. There was one exception to this described trend, but in this set of data the correlation coefficient was not good $(r=0 \cdot 50)$, and therefore the regression line may be unreliable.

\section{RELATIONSHIP BETWEEN INITIAL SIZE OF}

CATARACT AND RATE OF COMPACTION

Polynomial regression analysis of initial cataract size against the rate of compaction of the cataract revealed a trend of decreasing rate of compaction of cataract with decreasing initial cataract size. A summary of the regression analysis for first order (linear) and second order (quadratic) polynomials is presented in Table 3. The linear regression lines all showed a typical trend of decreasing rate of cataract compaction for smaller initial cataract size. Examination of the relevant sections of the quadratic regression functions revealed a trend of rapid compaction for larger cataracts, which tailed off towards a constant rate of compaction as the initial cataract size became smaller.

\section{Discussion}

CHANGE IN LENS COMPACTION WITH AGE

All individuals and families showed reduction in sagittal width and in equatorial diameter with increasing age. In some family groups the rate of reduction with age appears to be appreciably more rapid than in any of the individuals. This may be an artefact introduced by lack of identical genetic expression within each family at birth.

The rate of compaction of fibres is rapid in youth and decreases towards a constant slow compaction in about the third decade. The rate of compaction is also rapid for the initially large sized cataracts, and this 


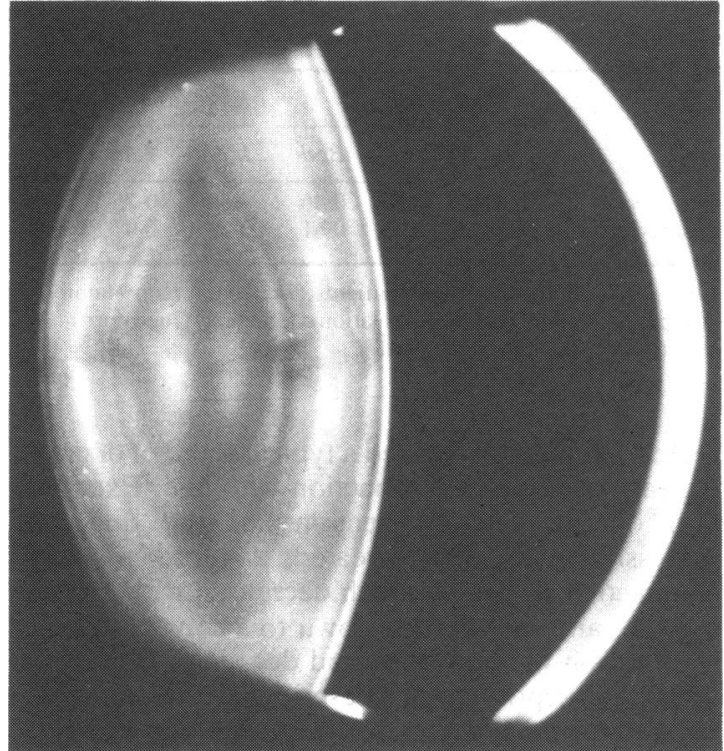

Fig. 8 The lens of a 45-year-old normal subject showing peripheral divergence of the cortical zones of discontinuity.

slows as cataracts get smaller. Because the lamellar cataracts examined become smaller with increasing patient age (saggital width, linear correlation coefficient $=0.83, \quad \mathrm{p}<0.0001 ;$ and equatorial diameter, linear correlation coefficient $=\mathbf{0} \cdot 81$, $\mathrm{p}<0.0001$ ), we can conclude that large lamellar cataracts are seen in young individuals, and that these rapidly compact down in youth to smaller slowly compacting cataracts in the older patients. From the previous study of initially subcapsular cataracts ${ }^{7}$ it was shown that cortical compaction was occurring in the lenses at all ages studied and that the rate of compaction was independent of the age of the individual. It was shown that the rate of compaction was faster the nearer the opacity was to the lens surface, and it was concluded that compaction was largely a cortical phenomenon. (We regard the nucleus as being the part of the adult lens which corresponds to that which comprised the whole of the lens at the time of the birth of the individual.) It can now be stated that compaction of lens fibres towards the centre of the lens affects all regions of the cortex and nucleus in youth and that the compaction becomes largely or completely confined to the cortex in middle age and beyond.

These findings are compatible with what is known of the change in physical characteristics of the nucleus and cortex with age. Fisher ${ }^{9}$ has shown that the elasticities of the lens cortex and nucleus change with age from a more deformable nucleus than cortex
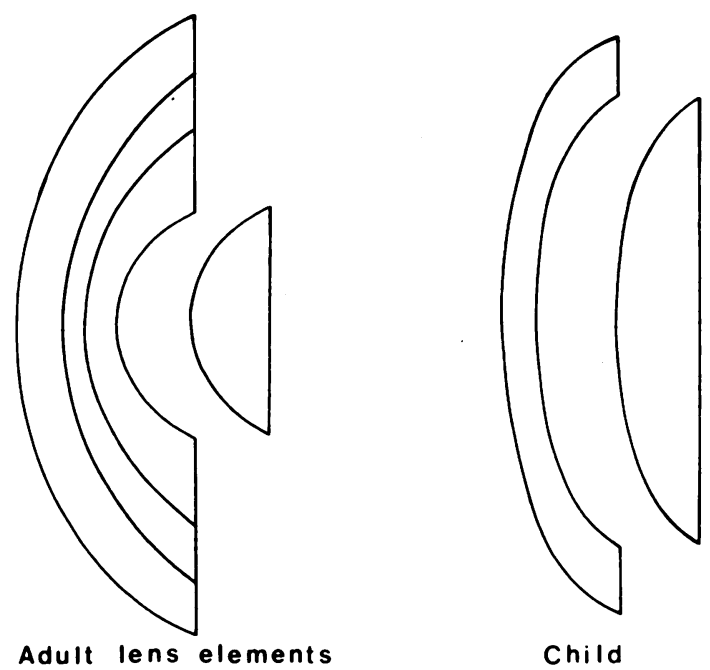

Fig. 9

in youth, to a less deformable nucleus with age. It seems probable that the change in Young's modules of elasticity with age that Fisher measured affects the ability of the lens fibres to compact and can account for the present observations that rapid fibre compaction affects the nucleus in youth and that this slows with age. Nordmann et al. ${ }^{10}$ showed that the dimensions of the nucleus increase with age, when the border of the nucleus is defined by the identification of the region of increased resistance to physical penetration of the lens. It is to be noted that the measurement of sagittal width of the nucleus by biomicroscopy ${ }^{41-13}$ and by slit-image photography $^{614} 15$ shows it to increase very little with age and that lens growth is mainly cortical. Nordmann and colleagues, findings ${ }^{10}$ of the apparent growth of the physically more resistant 'nucleus' with age are compatible with the present suggestion that the depth to which compaction proceeds becomes more superficial as the lens ages.

\section{CLINICAL SIGNIFICANCE}

The reduction in equatorial diameter with age of congenital lamellar cataracts should result in improving vision in the affected children. This was suggested ${ }^{16}$ from some early observations on congenital cataract. The reduction in diameter of lamellar cataracts with age is now confirmed, so it may be concluded that, in those cases in which mydriasis gives adequate vision in infancy, cataract extraction can be avoided. However, three families (not included in the present study) have been observed in which the cataract increases in size by the addition of new opaque lammellae superficial to the congenitally 
formed opaque lamella. Thus continuing observation is important.

\section{SHAPE OF NUCLEUS AND MAINTENANCE OF EMMETROPIA}

The tendency of the eye to maintain emmetropia, or in fact slightly increasing hypermetropia ${ }^{1718}$ through life, in spite of continuing growth of the lens has remained a fascinating enigma. This was conveniently explained by earlier workers, ${ }^{19}$ since Donder $\mathrm{s}^{20}$ described an increasing radius of curvature of the lens surfaces with age. Recent work demonstrates that the radius of curvature of the lens surfaces in fact become shorter with age. ${ }^{2122}$ This increased curvature of the lens surfaces would be expected to cause myopia, which does not normally occur, and therefore it must be offset by changes in the physical characteristics within the lens.

Our new data (regression line in Fig. 7) show that the outer lamellae of the lens are more lenticular in shape than are the inner lamellae. We are thus witnessing two processes of shape change in the lens. Firstly, the whole lens is becoming rounder (less lenticular) with age, and secondly the lamellar shells are becoming rounder with topographical passage deeper into the lens. It is this second process which gives rise to the peripheral divergence of the zones of discontinuity of the cortex, which is well seen in the 5 th decade (Fig. 8). Duke-Elder, ${ }^{23}$ who was not then aware of these changes in lens shape with age, proposed that the lens could be treated as three separate optical components: a biconvex nuclear element and two meniscus cortical elements (Fig. 9). The present study suggests that in terms of curvature the nucleus should become more positive with age. The cortex should become more negative with age, since the change in curvature is greater at the deep surface than it is at the outer surface (Fig. 9).

Duke-Elder considered that the lens would have maximal refracting power when the greatest difference in refractive index existed between the higher refractive index nucleus and the lower refractive index cortex and that such a lens would have greater refracting power than if it were a homogeneous structure of the higher of the two refractive indices. If the refractive indices of the nucleus and cortex remained unchanged with age, it might be expected that the increased curvature of the nucleus would more than offset the cortical negative change and induce myopia. It is thus necessary for the refractive index of the cortex to rise with age,,$^{24}$ but it cannot be assumed that the cortex is homogeneous in terms of refractive index, and it probably varies in the different zones of discontinuity. This seems highly probable, since the theory of light scatter in the normal lens relates scatter to refractive index..$^{25}$
The individual cortical zones of discontinuity have already been considered to be separate iso-indicial surfaces. ${ }^{26}$ Since these zones displaying peripheral divergence develop with age, they may be considered as individual negative lens elements when the refractive index of a particular zone exceeds that of the adjacent zones (Fig. 9).

In conclusion, it appears that emmetropia in aging is maintained by a balance between increasing refractive power of the lens due to increasing curvature of the lens surface and of the surface of the nucleus balanced by reducing refractive power due to an increasing refractive index in the cortex as a whole, and in individual peripherally divergent brightly scattering zones of discontinuity in the cortex in particular.

Lens growth throughout life by the continued mitosis of the lens epithelial cells to form new lens fibres may be inevitable, because the lens is an epithelial structure, but is more likely to be purposeful to ensure that the lens is always surrounded by a layer of young metabolically active fibres. The lens then has the task of accommodating these new fibres without excessive increase in size and without inducing myopia. This is achieved most beautifully by central compaction of the lens fibres asymmetrically, leading to the nucleus becoming more spherical and to peripheral divergence of the cortical zones of discontinuity.

\section{References}

1 Smith P. On the growth of the crystalline lens. Trans Ophthalmol Soc UK 1883; 3: 79-99.

2 Raeder JG. Untersuchungen über die Lage und Dicke der linse in menslischen Auge bei physiologischen und pathologischen Zuständen, nach einer neuen Methode gemessen. I: Die Lage und Dicke der Linse bei Emmetropen, Hypermetropen, und Myopen. Graefes Arch Clin Exp Ophthalmol 1922; 110: 73-108.

3 François J. Les cataractes congénitales. Rapp Soc Fr Ophthalmol. Paris: Masson, 1959: chapter 2: 38-52.

4 Huggert, A. The thickness of the cortex of the crystalline lens in different ages. Acta Ophthalmol (Kbh) 1946; 24: 43-62.

5 Luyckx J, Weekers J. Etude biométrique de l'oeil humain per ultrasonographie. 1. Les amétropies. Bull Soc Belge Ophtalmol 1966; 143: 552-67.

6 Brown N. Lens change with age and cataract. In: Ciba Foundation symposium on the human lens in relation to cataract. Amsterdam: Elsevier-Holland, 1973: 65-78.

7 Brown N. Dating the onset of cataract. Trans Ophthalmol Soc UK 1976; 96: 18-23.

8 Brown N. Quantitative slit-image photography of the lens. Trans Ophthalmol Soc UK 1972; 92: 303-17.

9 Fisher RF. The elastic constants of the lens. J Physiol (Lond) 1971; 212: 147-80.

10 Nordmann J, Mack G, Mack G. Nucleus of the human lens. III: Its separation, its hardness. Ophthalmic Res 1974; 6: 216-22.

11 Vogt A. Messende Untersuchungen über die Tiefenlage der Alterskernoberfläche in verschiedenen Lebensaltern. Graefes Arch Clin Exp Ophthalmol 1922; 109: 180-5.

12 Gallati J. Die relativen Dickenwerte von Rinde und Kern der menschlichen Linse in verschiedenen Lebensaltern. $Z$ Augenheilkd 1923; 55: 135-4. 
13 Caballero MLR, Gerhard JP, Nordmann J. Le noyau du cristallin humain. II: Son épaisseur. Arch Ophtalmol (Paris) 1973; 33: 425-8.

14 Goldmann H, Niesel P. Studien über die Abspaltungstreifen und das Linsenwachstum. Ophthalmologica 1963; 147: 134-42.

15 Brown N, Tripathi R. The loss of the anterior subcapsular clear zone of the lens. Prognostic significance in cataract formation. Trans Ophthalmol Soc UK 1974; 19: 29-45.

16 Brown N. Cataract in childhood. Photographic methods in assessment. Br J Ophthalmol 1977; 61: 135-40.

17 Brown EVL. Net average yearly change in refraction of atropinized eyes from birth to beyond middle life. Arch Ophthalmol 1938; 19: 719-34.

18 Slataper FJ. Age norms of refraction and vision. Arch Ophthalmol 1950; 43: 466-81.

19 Duke-Elder S. System of ophthalmology. London: Kimpton, $1961 ; 2: 320$

20 Donders FC. On the anomalies of accommodation and refraction of the eye. English translation by WD Moore. London: New Sydenham Society, 1984: 88.

21 Lowe RF, Clark BAJ. Radius of curvature of the anterior lens surface. Correlations in normal eyes and eyes involved with primary angle closure glaucoma. Br J Ophthalmol 1973; 57: 471-4.

22 Brown N. The change in lens curvature with age. Exp Eye Res 1974; 19: 175-83.

23 Duke-Elder S. Textbook of ophthalmology. London: Kimpton, 1932; 1: 736

24 Weale RA. The ageing eye. London: Lewis, 1963: 78.

25 Benedek GB. Theory of transparency of the eye. Appl Optics 1971; 10: 459-73.

26 Huggert A. Are the discontinuity zones of the crystalline lens isoindicial surfaces? Acta Ophthalmol (Kbh) 1946; 24: 417-21.

Accepted for publication 1 May 1987. 